\title{
Accepting uncertainty
}

\author{
Derek Richards \\ Editor, Evidence-based Dentistry \\ Evidence-Based Dentistry (2004) 5, 59. doi:10.1038/sj.ebd.6400283
}

In this issue Nigel Pitts finishes his series of articles about the jigsaw of Evidencebased dentistry and its three broad domains of research, dissemination and implementation, and we have a range of systematic reviews and randomised controlled trials covering issues from the use of radiographs in epidemiology, the longevity of restorations to appliances to treat temporomandibular pain dysfunction and sleep apnoea. Yet as the evidence base of dentistry is explored through the work of The Cochrane Oral Health group and other researchers using systematic reviews and conducting good quality research using robust study designs, we are discovering that there are relatively few certainties about the practice of dentistry.

But this is nothing new, for as clinicians we are faced with uncertainties in practice from day to day as patients present with a range of unpredictable and untimely conditions. Perhaps for the clinician, being able to acquire the skills to recognise, understand and master this uncertainty is one of the more important skills. To do this we need to be able to recognise our own skill, expertise and knowledge base. I hope that in our own way this journal helps in this regard.

For me the ongoing tension between what is known and what is unknown, what is certain and what is uncertain, is a driving force for evidence-based practice. It is also one of the core skills of evidence practice, critical appraisal, that helps the individual understand and deal with uncertainties in the existing evidence-base.

The latest version of the General Dental Council's document The First Five Years: ${ }^{1}$ sets out the Council's requirements on the content and scope of the 5-year programme for dental undergraduates. It states clearly that undergraduates 'should be able to evaluate the evidence and critically assess its relevance to treatment planning, advice and treatment provision'. This document also includes references to developing other key evidence-based skills such as literature searching and basic understanding of statistics. However there are a vast number of learning objectives contained within this document representing a crowded curriculum. I for one would welcome a move towards a more problem-based approach to learning within dental schools. I believe that not to do so perpetuates the traditional didactic approach which leads to dentists feeling as this individual in a quote from a paper by Baldwin et al: ${ }^{2}$

I feel that a career in dentistry, does not tax the intellect or stimulate the indivi- dual (who is obviously of above average intelligence) leading to a moribund professional life .... with very little variety.

A problem-based approach recognises uncertainty and consequently helps people understand and come to terms with it. For it is worth remembering that it is some time since Benjamin Franklin noted that "In this world, nothing is certain but death and taxes." And that uncertainty is also recognised by pure scientists, for it was in 1927 that the German physicist Heisenberg developed the Uncertainty Principle which, put simply states; that the more precisely the position of a particle is given, the less precicisely once can say what its moment is. This was an important moment in physics and the development of quantum theory. I find it interesting that we can accept readily uncertainty in a pure science like physics which has given us Heisenberg's Uncertainty Principle, yet we have much more difficulty accepting uncertainty in Health Sciences.

1. General Dental Council. The First Five Years: A Framework for Undergraduate Dental Education, 2nd edn. General Dental Council, London; 2002.

2. Baldwin PJ, Dodd M, Rennie JS. Postgraduate dental education and the 'new' graduate. Br Dent J 1998; 185:591-594. 